\title{
Novel 3D PZT thin film structure for micromechanics
}

\author{
F. Calame $\cdot$ P. Muralt
}

Received: 3 March 2006 / Accepted: 21 August 2006 / Published online: 7 March 2007

(C) Springer Science + Business Media, LLC 2007

\begin{abstract}
In this work, fabrication and properties of 3dimensional structures coated with piezoelectric $\mathrm{Pb}(\mathrm{Zr}, \mathrm{Ti})$ $\mathrm{O}_{3}$ (PZT) thin films have been studied in order to improve the piezoelectric coupling into the third dimension. Calotte layers have been chosen as demonstration devices. The base diameters range from 40 to $120 \mu \mathrm{m}$, the height varies between 10 to $40 \mu \mathrm{m}$. A dynamic, in-situ co-sputtering process allowing for in-situ growth was applied. Micromoulds were formed by wet etching in silicon. The etchant was a HNA solution ( $\left.\mathrm{HF}, \mathrm{HNO}_{3}, \mathrm{CH}_{3} \mathrm{COOH}\right)$ on a silicon dioxide mask. Calottes were obtained with the desired geometry and smooth surface state after few minutes etching time, and the use of chemical mechanical polishing (CMP). After deposition of the PZT membrane, deep silicon dry etching was then used to liberate the calotte layer. The dielectric constant and loss tangent of the calotte capacitors amounted to 830 and $5 \%$, respectively $(10 \mathrm{kHz})$. The fundamental resonance frequencies varied between 2.5 and $16.5 \mathrm{MHz}$, and were found to be inversely proportional to the base area of the calotte, the proportionality factor being $0.08 \mathrm{~Hz} \mathrm{~m}^{2}$.
\end{abstract}

Keywords PZT · Micromachining · Piezoelecric .

Thin films $\cdot$ MEMs

\section{Introduction}

The interest in piezoelectric microsystems (or MEMS) based on lead titanate zirconate (PZT) thin films has markedly increased. High frequency ultrasonic transducers

F. Calame $(\square) \cdot$ P. Muralt

Ceramics Laboratory, EPFL, Lausanne, Switzerland

e-mail: florian.calame@epfl.ch attract special interest because of suitable performances for airborne ultrasonic applications. The technology developed so far is limited to flat geometries. A new generation of MEMS could rise introducing the third dimension. The forces could be better focused into the right direction, and coupling factors increased.

The limitation to flat structures is partially due to the applied deposition technique and the missing microstructuration processes. Chemical solution deposition only works well if the substrate is flat. In case of large $3 \mathrm{~d}$-features, the spun on solution is thicker in depressions, thinner on elevations, and unevenly distributed on the walls. The most suited processes are the ones crystallizing the film in-situ, thus CVD [1], and in-situ sputtering [2]. CVD is certainly superior, because a very good conformality (step coverage) of film thickness is in general obtained. Sputtering works sufficiently well if the features are not too deep and do not exhibit too steep walls.

In many applications, the useful force direction is perpendicular to the substrate plane. A planar thin film, however, produces its piezoelectric forces along the substrates plane, and the vertical dilatation of the film is a too small effect. It thus needs a mechanism to redirect the force, or the excursion. This is for instance realized by means of a long cantilever (length $L$ ), where the in-plane forces create a bending leading to an excursion of the cantilever tip proportional to $L^{2}$. In the world of bulk devices, there are known structures with improved redirection capabilities not needing the bending mechanism (which reduces coupling). They work on the basis of the so-called flex-tensional mechanism [3, 4]. Moonies or cymbals as flex-tensional transducers consist of a piezoelectric disk sandwiched between two metal end-caps. The caps contain a shallow cavity on their inner surface. The cavities enable the caps to convert and amplify the small 


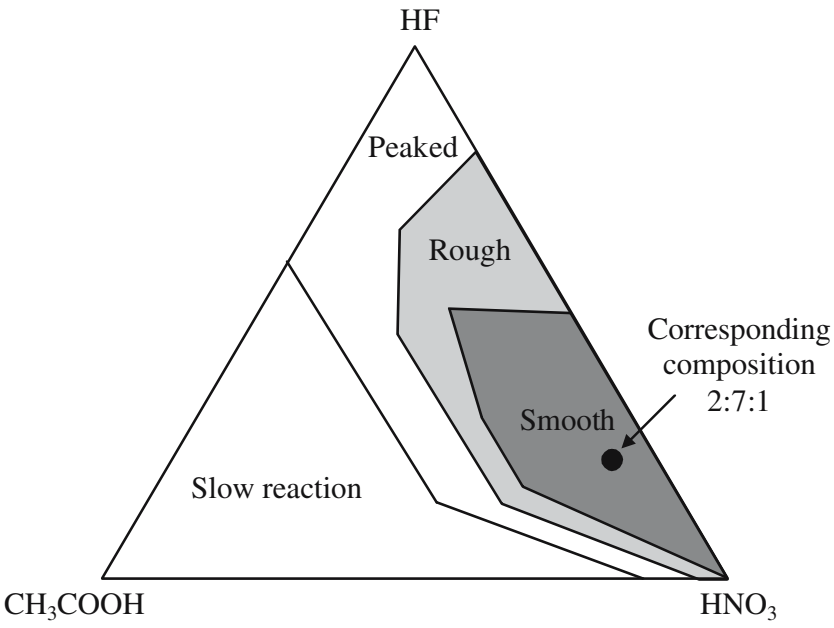

Fig. 1 Resultant geometry of the etched die as a function of the etchant composition in the HNA system [10]

radial displacement of the disk into a much larger axial displacement normal to the surface of the caps.

The major techniques to fabricate such 3D structures are micromoulds or sacrificial layers. Using a micromould consists of making a predefine structure into the silicon substrate by some dry or wet etching fabrication. Once the structure is realized, the replica will be formed by the PZT sputtered layer and the electrodes. By using sacrificial moulds, the structure is done on the silicon substrate by patterned photoresist [5] or electroless deposition [6] but there is limitation in the third dimension and on materials choice as the PZT is deposited at relatively high temperature $\left(600{ }^{\circ} \mathrm{C}\right)$.

The photolithographic step is of primary importance as the structure is in 3D. Electrodeposition of photoresist has been reported as an attractive method for 3D stacks of chips and interconnects [7,8], but it requires a conductive layer. Recently, a new coating method, direct spray coating of photoresist [9], has been introduced as a resist coating

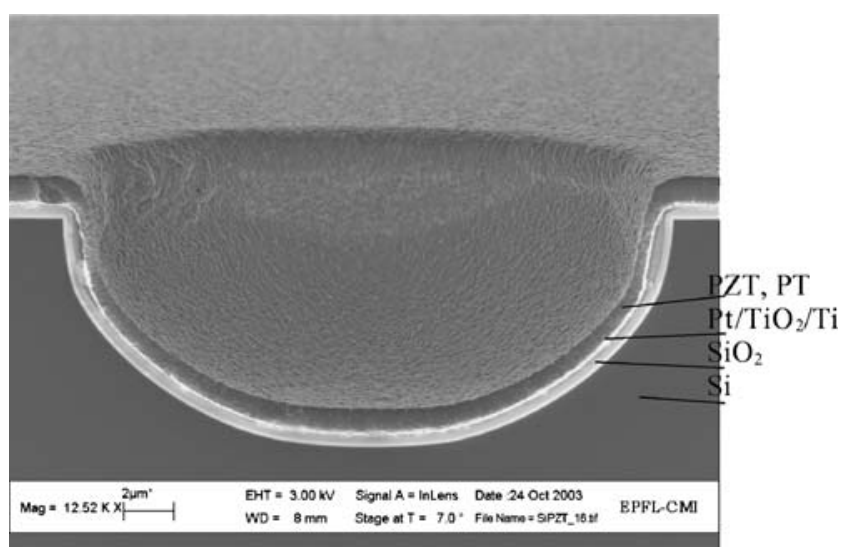

Fig. 2 Calotte with $\mathrm{Si}, \mathrm{SiO}_{2}, \mathrm{Ti}, \mathrm{TiO}_{2}, \mathrm{Pt}, \mathrm{PbTiO}_{3}$ and $\mathrm{PZT}$

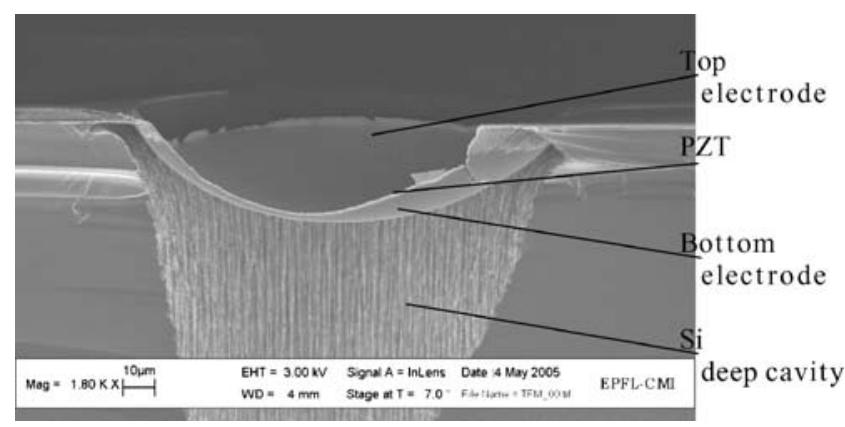

Fig. 3 Released calotte with Pt bottom electrode, PZT and Pt top electrode

technique specifically for MEMS. Although this technique is still in the early stages of exploration, it appears to be a promising technique for coating irregular surfaces as it presents some advantages over spin coating and electrodeposition of photoresist.

\section{Experimental}

The micromould technique was chosen to perform the 3D structures. The device microfabrication process is based on five masks. Starting with a $100 \mathrm{~mm}$ double side polished wafer, thermally wet oxidized silicon oxide was deposited to form the mask for post isotropic wet silicon etching performed by HNA solution (Hydrofluoric acid (49\%), Nitric acid (69\%) and Acetic acid) to form calottes used as micromould for subsequent deposition and patterning.

In the HNA solution, the nitric acid acts as an oxidant. Then follows a reaction of the oxidized Si fragments with $\mathrm{OH}^{-}$and subsequent dissolution of the silicon oxidation products in $\mathrm{HF}$ :

$\mathrm{HNO}_{3}+\mathrm{H}_{2} \mathrm{O}+\mathrm{HNO}_{2} \rightarrow 2 \mathrm{HNO}_{2}+2 \mathrm{OH}^{-}+2 \mathrm{~h}^{+}$

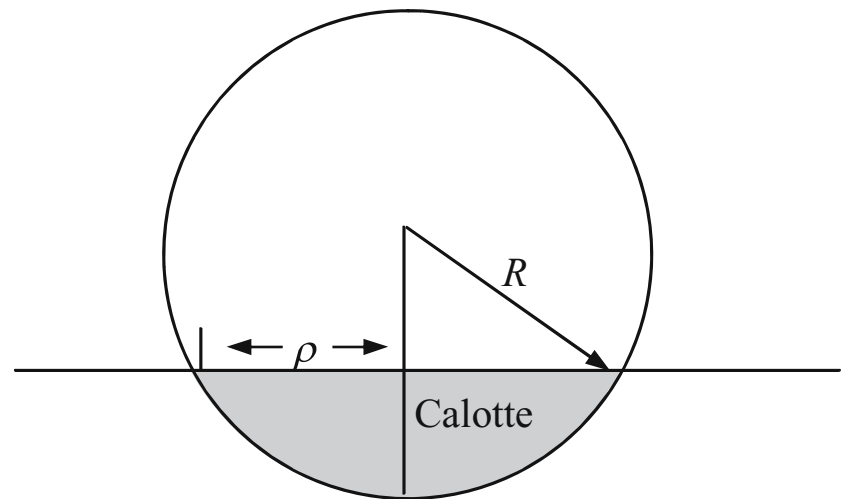

Fig. 4 Schematic view of the calotte with radius of curvature $R$ and opening $\rho$ 


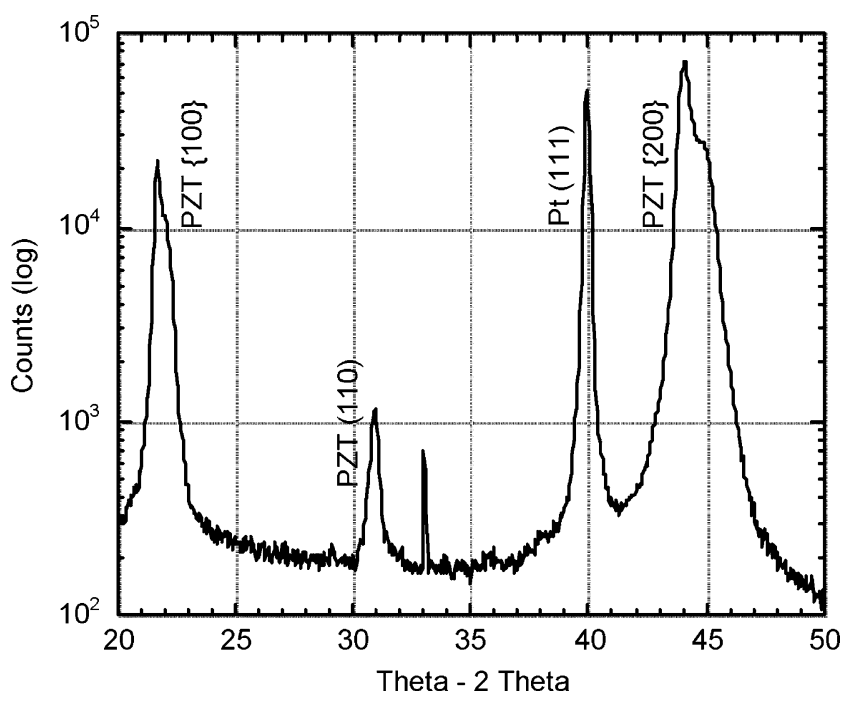

Fig. 5 X-ray pattern of sputtered PZT film showing (100) and (200) preferred orientation

After, $\mathrm{OH}^{-}$groups attach to the oxidized $\mathrm{Si}$ species to form $\mathrm{SiO}_{2}$, liberating hydrogen in the process:

$\mathrm{Si}^{4+}+4 \mathrm{OH}^{-} \rightarrow \mathrm{SiO}_{2}+\mathrm{H}_{2}$

Hydrofluoridric acid (HF) dissolves the $\mathrm{SiO}_{2}$ by forming the water-soluble $\mathrm{H}_{2} \mathrm{SiF}_{6}$. The overall reaction of HNA with $\mathrm{Si}$ is typically:

$\mathrm{Si}+\mathrm{HNO}_{3}+6 \mathrm{HF} \rightarrow \mathrm{H}_{2} \mathrm{SiF}_{6}+\mathrm{HNO}_{2}+\mathrm{H}_{2} \mathrm{O}+\mathrm{H}_{2}$

Figure 1 [10] shows the resultant geometries of the etched die as a function of the etchant composition. As we want smooth and specular surfaces, 2:7:1 $\left(\mathrm{HF}: \mathrm{HNO}_{3}\right.$ : $\mathrm{CH}_{3} \mathrm{COOH}$ ) composition was chosen.

After HNA wet etching, the $\mathrm{SiO}_{2}$ mask was removed. The surface of the wafer is then grinded down by chemical mechanical polishing (CMP) to reduce the slope at the border of

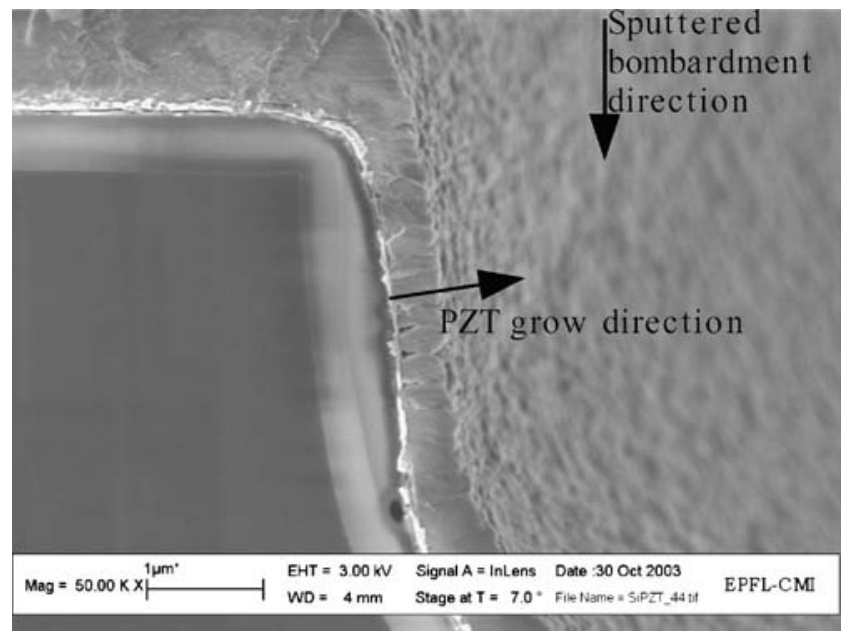

Fig. 6 Perpendicular growing of PZT even on surface nearly perpendicular to the PVD bombardment direction

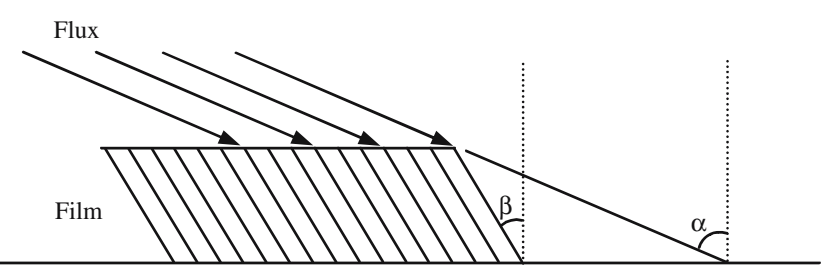

Substrate

Fig. 7 Deposition geometry of a sputtered film [11]

the calotte. The wafer was reoxidized by thermal wet oxidation. A barrier layer of $\mathrm{Ti}^{2} / \mathrm{TiO}_{2}(2 \mathrm{~nm} / 20 \mathrm{~nm})$ and a platinum bottom electrode of $100 \mathrm{~nm}$ were sputtered on the $\mathrm{SiO}_{2}$ at $300{ }^{\circ} \mathrm{C}$ using a Balzers BAS 450 . The Pt layer was patterned using spray coated photoresist. This layer was dry etched with the STS Multiplex. A thin (100)-oriented $\mathrm{PbTiO}_{3}$ (PT) seed layer and $1 \mu \mathrm{m}\{100\}$ PZT were grown on the bottom electrode using PVD process with a Nordiko 2000 (Fig. 2). Subsequent patterning of PZT was performed using spray coated PR. A Pt top electrode was sputtered at room temperature and patterned by lift-off again with spray coated PR.

The last step is to liberate the calottes. Backside deep silicon anisotropic dry etching (Bosh process) with $\mathrm{SF}_{6}$ and $\mathrm{C}_{4} \mathrm{~F}_{8}$ was used. The $\mathrm{SiO}_{2}$ was removed by dry etching in $\mathrm{CF}_{4}$ gas. The Pt bottom electrode serve as and etch-stop. The calotte-membrane thus consists of platinum bottom electrode, PZT and platinum top electrode (Fig. 3). Figure 4 shows a schematic view of the geometry of the calotte view the curvature radius $R$ and the opening radius $\rho$.

\section{Results and discussion}

X-ray diffraction pattern has been performed on the PZT to confirm the $\{100\}$ orientation of PZT $45 / 55$ (Fig. 5).

The grain morphology is the same everywhere. The PZT grains are growing perpendicular to the bottom electrode, even on vertical wall at the edge of the calotte (Fig. 6). This growth property seems to be astonishing for a sputter process, but is explained by the large mobility of the adatoms at the growth temperature of $570{ }^{\circ} \mathrm{C}$.

Normally, it should grow as $\tan \alpha=2 \tan \beta$ as reported by Nieuwnhuizen and Haanatra in 1966 [11] (Fig. 7). It follows more the way of growing as CVD film where the reactants are absorbed on the heated substrate surface and the adatoms undergo migration and film-forming reactions. Then a surface diffusion takes place, nucleation and finally growth of the film. So, in our case, we can see that the surface diffusion is predominant compare to ion bombardment.

Table 1 Resonance frequency of different size of calottes.

\begin{tabular}{llllll}
\hline Calotte's radius $\rho[\mu \mathrm{m}]$ & 35 & 40 & 45 & 50 & 55 \\
\hline Resonance frequency [Mhz] & 16.5 & 9.1 & 6.9 & 5.6 & 2.5 \\
\hline
\end{tabular}




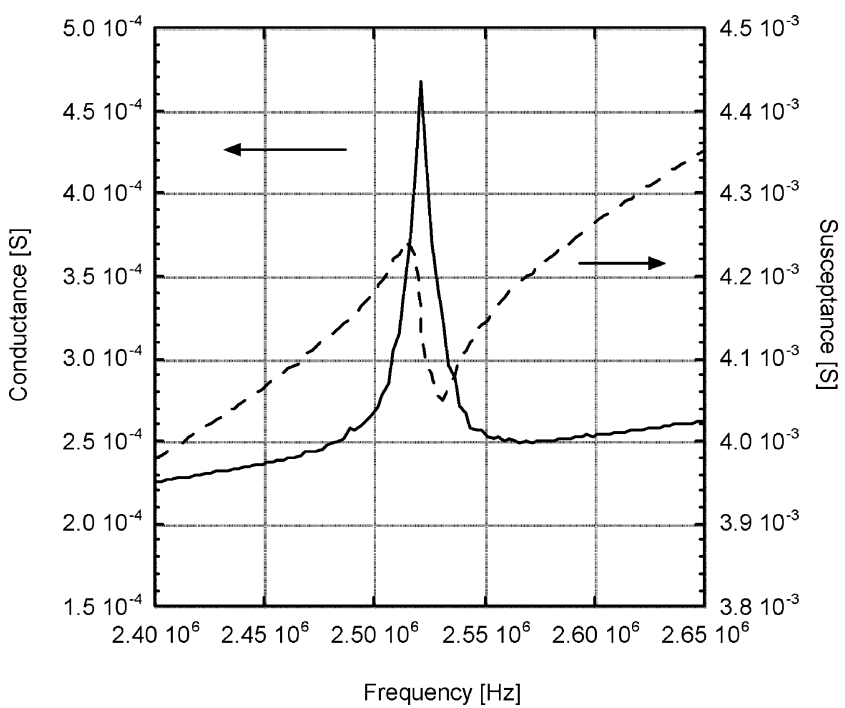

Fig. 8 Admittance curve of a $110 \mu \mathrm{m}$ in diameter calotte

The released structure has been characterized using an impedance analyzer. The dielectric constant and loss tangent of the calotte capacitors amount to 800 and 5\% respectively at $10 \mathrm{kHz}$. The fundamental resonance frequencies vary between 2.5 and $16.5 \mathrm{MHz}$ (Table 1). Figure 8 shows the real and imaginary part of the admittance curves of a calotte with $110 \mu \mathrm{m}$ of diameter at the resonance frequency vibrating at $2.5 \mathrm{MHz}$.

The resonance frequencies were found to be inversely proportional to the square of the base radius $\rho$ (Fig. 9) as:

$f_{\mathrm{r}}=\frac{0.08\left[\mathrm{~Hz} \cdot \mathrm{m}^{2}\right]}{\pi \rho^{2}}$.

This is the same dependence on $\rho$ as for a flat clamped plate, however, with a considerably higher prefactor.

The low frequency amplitude was measured with an AFM. A long tip was used in order to have contact with the bottom of the $40 \mu \mathrm{m}$ deep calotte. A responsivity of $3.5 \mathrm{~nm} / \mathrm{V}$ were observed, which is an estimated factor 200 times higher than $d_{31}$. This shows that the PZT layer is active and that there are no open or short circuits along the top electrode and between top and bottom electrode. It shows as well that the shape of this calotte structure gives an excellent deflection response compare to the deformation of the PZT layer itself $\left(d_{31}\right)$.

\section{Conclusion}

Calotte membranes consisting of Pt bottom electrode, PZT and Pt top electrode were successfully developed and microfabricated. Fundamental frequencies vary between

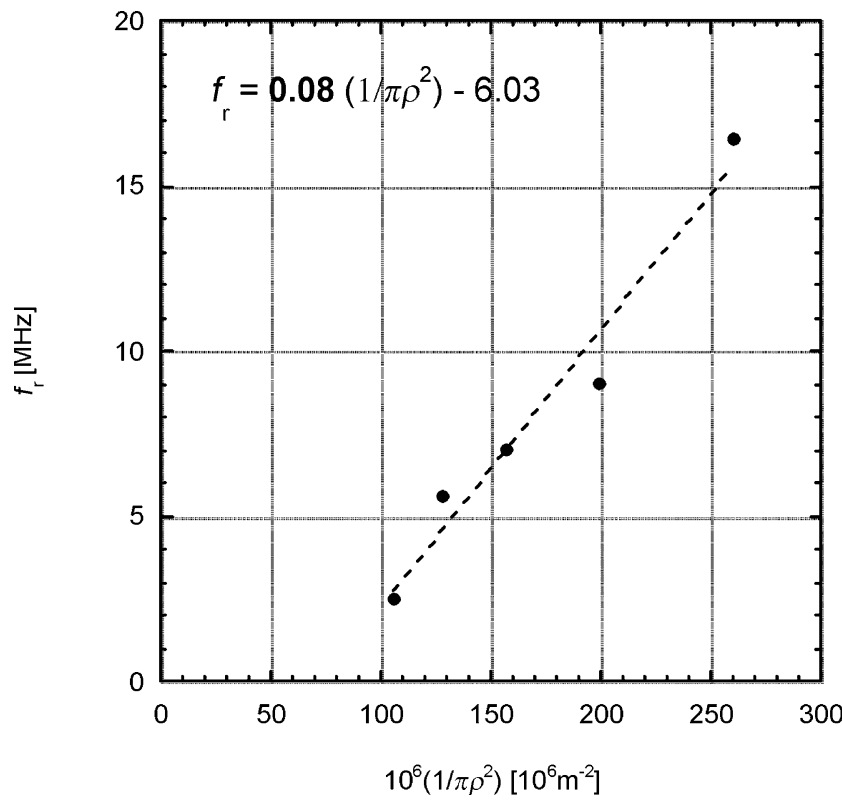

Fig. 9 Resonance frequency function of the inverse base area of the calotte

2.5 and $16.5 \mathrm{MHz}$ and the PZT layer along the calotte is active when applying an $\mathrm{AC}$ field giving a response of $3.5 \mathrm{~nm} / \mathrm{V}$. Further work will be performed to improve materials design and theoretical understanding.

Acknowledgment This work was supported by the Swiss Office for Education and Science (OFES) and the European commission in the frame of the European projects MUSTWIN and MEMSPIE. The author would like to thank Sandrine Gentil for all the chemistry preparation and the CMI staff for their constant help in the clean room.

\section{References}

1. M. Okada et al., J. Appl. Phys. 28, 1030-1034 (1989)

2. S. Hiboux, P. Muralt, T. Maeder, J. Mater. Res. 14, 4307-4318 (1999)

3. J. Zhang et al., Ultrasonics 39, 91-95 (2001)

4. R.J. Meyer Jr. et al., Sens. Actuators, A 87, 157-162 (2001)

5. N. Chomnawang, J.-B. Lee, On-chip $3 D$ micro-inductor for highfrequency applications using deformation of sacrificial polymer (Department of Electrical and Computer Engineering, Louisiana State University, Baton Rouge)

6. NMRC, http://www.nmrc.ie

7. C. Christensen et al., IEEE Trans. Compon. Packaging Manuf. Technol. A, 19(4), 516-522 (1996)

8. S. Linder et al., Photolithography in anisotropically etched grooves, in Proc. 9th IEEE MEMS 96 Technical Digest, pp. 3843 (1996)

9. M. Parodi et al., Semicond. Int. 19(1), 101-106 (1996)

10. B. Schwartz, H. Robbins, J. Electrochem. Soc. 123(12), 1903 1909 (1976)

11. J.M. Nieuwnhuizen, H.B. Haanatra, Philips Tech. Rev. 27, 87 (1966) 